\title{
Helping the child in the emergency room
}

Lara Šuštar Pennone

\section{Izvleček}

Otrokovo razumevanje bolezni ali poškodbe in s tem tudi njegovo doživljanje nujnega sprejema se spreminjata glede na njegovo starost in razvojno stopnjo mišljenja. Za ustrezno komunikacijo z njim in lajšanje stiske, ki jo doživlja, je izjemnega pomena poznavanje posebnosti razvojnih stopenj in njim primernih pristopov. Dojenčku ali malčku do drugega leta starosti najbolj pomagajo božanje, prepevanje in zibanje, s čimer pozornost usmerjamo stran od bolečine. Otroku med 2. in 6.-7. letom starosti, za katerega je značilen buren razvoj domišljije, pomagamo tako, da mu starosti primerno pojasnimo, kaj se dogaja, s čimer preprečimo napačne ali pretirane predstave o tem, kaj ga še čaka. Z njegovo domišljijo si lahko tudi pomagamo tako, da uporabljamo čarobne predmete ali lastnosti, ki lajšajo neprijetnost ali bolečino. Med 6.-7. in 11.-12. letom starosti otroku opišemo, kaj počnemo in kakšen je načrt ter preusmerjamo pozornost. Slednje izvedemo tako, da mu npr. omogočimo, da nam pomaga, ali ga zaposlimo z miselnimi nalogami. Po 12. letu starosti je predvsem pomembno, da upoštevamo mladostnikovo zasebnost in njegovo morebitno željo po odsotnosti staršev. $\checkmark$ vsakem primeru, ne glede na starost, pa otroku nikoli ne skušamo prikriti, da bo poseg morda neprijeten in boleč.

Ključne besede: bolečina, zdravljenje bolečine, komunikacija, otrok.

\section{Abstract}

A child's understanding of illness or injury and consequently his/her experience of emergency admissions changes according to his/her age and developmental stage. Knowing the specifics of different developmental stages helps us to adjust our communication, pain-relief approaches, and distraction techniques. Infants and toddlers up to 2 years of age are best helped by distraction techniques like caressing, singing, rocking, which take their focus away from the pain. Children between the ages of 2 and $6-7$ years are known for quickly developing fantasies. Age-appropriate explanations about what is happening and what will happen prevent them from developing wrong or exaggerated perceptions. We can take advantage of their fantasy by using magical objects or properties, which help to relieve pain. Between $6-7$ and 11 - 12 years, children need explanations of the procedures and plan and distraction techniques. We can allow them to help us wherever they can or keep them busy with different cognitive tasks. After 12 years of age, it is paramount to consider the adolescent's need for privacy and his/her possible wish for his/her parents not to be present. Regardless of the age of the child, we must never lie about possible pain or discomfort of planned procedures.

Key words: pain, pain management, communication, child. 


\section{Otrok na urgenci}

Obravnava v urgentni ambulanti je nekaj, kar lahko doživi kdor koli iz najrazličnejših razlogov. Ker je ne moremo predvideti, se otrok in starši nanjo ne morejo pripraviti. Skupni imenovalec vseh obiskov nujne pomoči so negotovost, občutje nemoči in izgube nadzora, pregledi in preiskave, posegi in pogosto tudi bolečina. Najpogostejši boleč zdravstveni poseg pri otrocih ${ }^{1}$, ki številnim povzroča pomembno stisko tako zaradi bolečine kot zaradi strahu oz. pričakovanja bolečine, je zbadanje z injekcijsko iglo, a lahko pri majhnih otrocih stisko izzovejo že ppri mlajših otrocih (1). Akutno ogrožajoča stanja izzovejo še bolj intenzivna stres in strah pred tem, kaj se bo zgodilo, sploh če je otrok deležen pogostih, ponavljajočih se in bolečih zdravstvenih posegov. Tovrstni posegi lahko izzovejo tesnobo, spremenjeno vedenje, frustracijo, jezo, žalost in depresivnost ter posttravmatski stresni sindrom (1). Poleg samega vzroka obravnave na otrokovo doživljanje vplivajo tudi njegove značilnosti (starost in razvojna stopnja, spol, temperament, anksioznost, strategije spoprijemanja s stresom, pričakovanja, spomini na pretekle boleče izkušnje, miselne sposobnosti), značilnosti staršev (kulturološki dejavniki, spol, anksioznost, pričakovanja, vedenje) in profesionalni dejavniki (tehnične kompetence, farmakološke intervencije, vedenje, terapevtski odnos) (1).

\section{Pomen otrokove starosti na razumevanje}

Nekoč je veljalo, da vsi ljudje podobno razumemo koncept bolezni ali poškodbe. Razumevanje teh konceptov so raziskovalci sprva preverjali pri odraslih. Ugotovili so, da imajo odrasli ljudje različne predstave o tem, kaj pomeni biti bolan ali poškodovan. Vzroke razlik v razumevanju so pripisovali predvsem

\footnotetext{
1 Zaradi preglednosti prispevka izraz 'otrok' upora bljamo za vsa starostna obdobja, tj. od novorojenč ka do mladostnika, razen, kjer je navedeno drugače. Izraz 'starši' se nanaša na starše, skrbnike ali otrokove spremljevalce.
}

razlikam v kakovosti komunikacije med zdravnikom in bolnikom. Raziskovanje razumevanja bolezni ali poškodbe se je kmalu razširilo tudi na otroke. Že pred več kot 30 leti so raziskovalci ugotavljali, da imajo odrasli pogosto napačno predstavo o otrokovem doživljanju lastne bolezni in tudi zdravljenja, saj razvoj mišljenja pri otroku poteka specifično. Doživljanje otroka se odraslim lahko zdi bizarno in nepredvidljivo (2).

Danes vemo, da se otrokovo znanje o telesu in njegovemu delovanju, o vzrokih in posledicah bolezni, o preprečevanju poškodb in o zdravljenju razvija na sistematičen način. Pri razumevanju igra največjo vlogo otrokova starost, otroci pa prej kot bolezen ustrezno razumejo poškodbe (2). S tem znanjem svojo komunikacijo in vedenje med obravnavo v urgentni ambulanti lažje prilagodimo otroku ter razumemo na videz nenavadna vedenja otroka ali njegovo nesodelovanje. Zelo podobna vodila za razumevanje, komunikacijo in pomoč otrokom veljajo tudi v drugih zdravstvenih okoljih, npr. pri pregledih na splošno, pri drugih manjših zdravstvenih posegih ali med bolnišničnim zdravljenjem.

\section{Pomoč različno starim otrokom}

Razvojna faza mišljenja dojenčka, otroka in mladostnika vpliva na to, kako razume svet in kako pride do znanja o njem. Za lažje razumevanje otrokovega dojemanja sveta in s tem bolezni ali poškodbe si lahko pomagamo s štirimi stopnjami razvoja mišljenja, kot jih je opredelil Piaget: senzomotorična, predoperativna, konkretno operativna in formalno operativna stopnja (3). Razumevanje otrokovega doživljanja njegove bolezni ali poškodbe pomembno vpliva na to, kako mu lahko pomagamo med urgentno obravnavo, ki s seboj prinaša negativne občutke, pogosto neprijetne zdravstvene posege ali ločitev od staršev. Z znanjem o otrokovem doživljanju lahko pomembno prispevamo k zmanjšanju njegove psihološke stiske med spreje- mom (4) in povečamo otrokovo sodelovanje. Če otrok npr. ne razume namena urgentnega sprejema, ga lahko dojame kot nekaj negativnega ali nepotrebnega (5) in temu primerno med posegom manj sodeluje ali sploh ne sodeluje.

Senzomotorična stopnja je značilna za otroke od rojstva do drugega leta starosti. V tem starostnem obdobju se otrok o svetu uči predvsem skozi gibanje in zaznavanje informacij preko čutil. Razvije se doživljanje stalnosti predmeta, kar pomeni, da otrok začne razumeti, da predmet ali oseba obstaja, tudi če je ne more videti, slišati ali se dotakniti (3). Ker otrok razume, da starša ni več ob njem, hkrati pa si še ne zmore razložiti, kam, zakaj in za koliko časa je odšel in je zato v stiski, lahko potek nujnega sprejema dodatno oteži ločitvena tesnoba (1). Otroci ne razmišljajo, kaj je bolezen ter zakaj in kako se pojavi (6). O njihovi bolečini lahko sklepamo le preko fizioloških odzivov in po spremembah v vedenju, saj starši poročajo, da se otrok vede drugače kot navadno. Pride lahko do agresivnih izbruhov ter zmanjšane ali povečane aktivnosti (1). Dojenčku ali malčku v urgentni ambulanti pomagamo tako, da mu ponudimo tolažilno sladkano dudo, ga pestujemo, zibamo, mu pojemo, se z njim pogovarjamo, ga masiramo in božamo ter s tem odvračamo pozornost od posegov (7).

Predoperativna stopnja se pojavi med 2. in 6.-7. letom starosti. Otrok razvija in potrebuje simbole, kot so besede, geste, igra in risanje. Značilen je egocentrizem - otrok svet vidi skozi lastno perspektivo in verjame, da tudi ostali vidijo in razumejo svet enako kot on. Mišljenje je magično, v ospredju sta fantazija in domišljija (3). V raziskavah (8) ugotavljajo, da otroci bolezen razumejo kot fenomen - razlaga bolezni je nepopolna, otrok ne zmore razložiti vzroka bolezni, če že, pa je to navadno okužba. Razlikovanje med različnimi boleznimi se pojavi šele pri koncu te razvojne faze. Ker je za to stopnjo značilno magično mišljenje, lahko otroci vzrok bolezni pripišejo dogodkom, ki nimajo nikakršne povezave z boleznijo. Otrok tako lahko ver- 
jame, da je na primer poškodba kazen za neprimerno obnašanje v preteklosti, ker je po stanovanju hodil bos kljub navodilu staršev, naj obuje copate. Ker še ne razume konceptov količine in trajanja, si ne zna predstavljati, kaj pomeni, da bo nekaj trajalo samo minuto ali da bo samo malo bolelo (1). Časovni obseg posega otroku razložimo na konkretnih primerih, na primer »trajalo bo tako dolgo kot« otroku ljuba pesmica ali risanka, ter da neposredno pred posegom dokaj natančno in počasi razložimo, kaj nameravamo narediti, pri tem pa si pomagamo z lutko ali medvedkom. Tako preprečimo fantaziranje in izkrivljeno predstavo o samem posegu. Opišemo, kako se bo najverjetneje počutil (npr. »Lahko te bo peklo, ščemelo, tiščalo, zbadalo ..., dokler ne preštejem do deset.«, »Kot bi pičila čebela ali komar.«) in kako lahko sam sodeluje (»Vzemi s seboj priljubljeno igračo.«, "Globoko in počasi dihaj.«, »Igrajva se besedno igro.«). Zagotovimo ravno toliko informacij, kot jih lahko prenese. Preveč informacij je lahko prav tako neustrezno in obremenjujoče kot premalo (1). Otrokovo razumevanje preverimo tako, da sam še enkrat pove, kako bo poseg potekal, saj si zaradi slabše razvite pozornosti najverjetneje ne bo zapomnil vseh informacij in navodil (1). Nikoli ne obljubljamo, da poseg ne bo boleč, če vemo, da je boleč (9). Prav tako ne obljubljamo, česar ne moremo zagotoviti ali če v resničnost izjave nismo prepričani, npr. »Samo še nogo poslikamo, pa greš domov.«ali »Ko se zbudiš, bosta zraven mami in ati.« Izogibanje takšnim in podobnim obljubam sicer velja za otroke vseh starostnih skupin in njihove starše.

Ideje, kako otroku med 2. in 6.-7. letom starosti pomagamo med obravnavo $\mathrm{v}$ urgentni ambulanti (10):

- Izkoristimo otrokovo magično mišljenje in njegovo fantazijo: »Predstavljaj si, da imaš čudežno rokavico, ki bolečine ne spusti naprej.»

- Pomagajmo mu razumeti časovni potek zdravstvenega posega: »Ko do konca zapojeva »Kuža pazi«, bo mimo.«
- Če je mogoče, mu omogočimo soodločanje: »Ti kri vzamem iz leve roke ali iz desne roke? « Pozorni smo, da mu ne dajemo možnosti izbire tam, kjer je v resnici ni, npr. »Ali greš slikat nogo?«

- H globokem dihanju ga spodbujamo s prispodobami, npr. da dihamo, kot bi pihali milne mehurčke.

Po končanem posegu oz. pregledu otroka nagradimo s štampiljko, nalepko in podobnim, pri čemer pazimo, da otroka nagradimo za sodelovanje ()Čeprav je šivanje bolelo in so ti tekle solze, si z mano prepeval pesmico in si tako pomagal, bravo!«) in ne za ,stoično' prenašanje situacije ("Čisto nič nisi jokal, si pravi fant!«).

Konkretno operativna stopnja je značilna za otroke med 6.-7. in 11.-12. letom starosti. Razvija se logično mišljenje, ki pa še ni tako razvito kot pri odraslih. Otroci zmorejo manipulirati z informacijami, ki jih dobijo iz okolice, in iz njih racionalno sklepati (3). Večina otrok razloži, da se bolezen prenese preko telesnega stika. Otroci tako že razumejo, da lahko zbolimo, če se nečesa dotikamo, in npr. razumejo pomen higiene rok. Razumejo, da lahko zbolimo, ker nekaj od zunaj prenesemo v telo preko hranjenja ali dihanja, a je njihova razlaga zaradi slabšega poznavanja anatomije in funkcij telesa nepopolna. Otrok tako npr. pove, da se prehladimo, če nekdo kihne v dlan, mi pa se te dlani dotaknemo (11). Določeni elementi magičnega ali nerealnega razmišljanja, značilni za predoperativno stopnjo mišljenja, lahko vztrajajo tudi v tej fazi otroštva. Kljub bolj realnemu zavedanju doživljanja lahko otrok še vedno za dogodek krivi npr. svoje vedenje, zato mu lahko pomoč nudimo tudi z uporabo strategij, ki smo jih našteli v prejšnjem odstavku.

Zaradi bolj naprednega razumevanja bolezni otroci na konkretno operativni razvojni stopnji ugotovijo, da lahko aktivno prispevajo k temu, da ne zbolijo oz. da hitreje ozdravijo (6). Otroku $v$ urgentni ambulanti pomagamo in ga pripravimo na poseg tako, da mu razložimo, kako poteka. Če je možno, ga povabimo $k$ sodelovanju in ga vprašamo, kaj želi, da naredimo najprej in kaj pozneje. Uporabimo igrice, ki ga odvrnejo od dogajanja, povezanega z bolečino (9), npr. (7):

- Pomagamo si z miselnimi igrami: „Dajva, spomniva se čim več besed, ki se začnejo na isto črko kot tvoje ime."

- Otroka zaposlimo tako, da nam pomaga pri pripravi materiala: »Ti odtrgaj mikropor, jaz pa bom pripravil vse ostalo."

- Učimo ga pozitivnega samogovora: »Jemanje krvi si že večkrat dal skozi in ga uspešno prenesel.»

Otroka ne kritiziramo (»Fant pred tabo je bil pa bolj priden.«) in ne zagotavljamo, da ne bo bolelo. Formalno operativna stopnja se pojavi med 11. in 12. letom starosti. Za njo je značilno, da mladostnik zmore razmišljati abstraktno ter je sposoben ustvarjanja in preverjanja hipotez (3). Pojavi se razumevanje fizioloških in psiholoških dejavnikov bolezni. Mladostniki razumejo, da je bolezen lahko posledica nepravilnega delovanja notranjih organov. Začne se zavedati povezave med psihološkim stanjem in fiziološkimi simptomi. Mladostnik tako na primer razloži, da lahko utrpimo srčno kap zaradi preveč stresa, ki vpliva na naš krvni tlak in s tem na srce (11). Mladostnikom posredujemo obširna pojasnila. Če je možno, si vzamemo čas za razlago postopkov in odgovorimo na njihova vprašanja. Spodbujamo jih, da sodelujejo. Poseben poudarek namenimo zasebnosti med posegi. Mladostnik si v tem obdobju morda ne želi prisotnosti staršev, kar preverimo in želje tudi upoštevamo. Pustimo mu, da potek sprejema nadzoruje, kolikor je mogoče (9). Tudi mladostnikom lahko olajšamo doživljanje zdravstvenega posega s podobnimi tehnikami kot mlajšim otrokom (10). Zaradi bolj realne predstave, kaj bolezen ali poškodba pomeni in kakšne so njene posledice, lahko mladostniki informacije o morebitni diagnozi doživljajo bolj čustveno. Ob seznanjanju z diagnozo, potekom zdravljenja in morebitnimi zapleti 
moramo biti pozorni na mladostnikovo čustveno doživljanje in temu ustrezno prilagoditi komunikacijo.

\section{Kaj pa starši?}

Izsledki raziskav (12) kažejo, da je bolj kot prisotnost ali odsotnost staršev ob bolečem posegu pomembno to, kako se starši odzivajo. Tesnoba staršev vpliva na tesnobo otrok in s tem na učinkovitost spopadanja s situacijo. Starši lahko otroku najbolj pomagajo tako, da se z njim pogovarjajo o drugih temah, uporabljajo humor ali usmerjajo otroka, kako naj si pomaga pri obvladovanju bolečine. Po drugi strani so pomirjanje, opravičevanje in kritiziranje manj koristna dejanja kot prej naštete tehnike (12). Če je možno, staršem namignemo, kako lahko z omenjenimi tehnikami in pristopi pomagajo otroku pri lajšanju stiske med pregledom. Če je situacija za starše preveč stresna in s svojo stisko dodatno neugodno vplivajo na otrokovo spopadanje s stresom, staršem zagotovimo, da se lahko umaknejo in se sprostijo, preden se vrnejo nazaj.

Poleg otroku prilagojene komunikacije in uporabe tehnik za lajšanje bolečine je v urgentni ambulanti izjemno pomembna tudi učinkovita komunikacija s starši. Je temelj uspešnega odnosa med medicinskim osebjem, otrokom in starši (17), izboljšuje uspešnost zdravljenja in zadovoljstvo z zdravljenjem, pri starših in s tem tudi otrocih pa zmanjšuje stisko in povečuje zaupanje (16). Enako pomembno pa je uspešna komunikacija zdravstvenega osebja povezana s poklicnim zadovoljstvom, uspešnostjo in samozavestjo zaposlenih (15).

Posebnost dela $v$ urgentni ambulanti so okoliščine, ki navadno zahtevajo kratke in zahtevne pogovore, v katerih je veliko negotovosti oz. potrebe po informacijah, ki jih morda (še) nimamo. Ko komuniciramo s starši, upoštevamo zasebnost družine tako, da se s hodnikov ali iz čakalnic umaknemo v pri- meren, zaseben in miren prostor, kjer lahko sedimo (12). Govorimo jasno in preprosto, saj raziskave (14) kažejo, da starši že ob nenujnih sprejemih otroka prvih informacij zdravstvenega osebja ne razumejo ustrezno, včustveno intenzivnih situacijah, kot je urgentni sprejem, pa je razumevanje še slabše. Starši poročajo, da se bolj kot informacij, ki so jih prejeli od zdravstvenega osebja, spominjajo svojih čustev, zmedenosti, nemoči in »občutka, da si v megli« (13). Zato je smiselno preveriti njihovo razumevanje povedanega, bistvene informacije pa tudi večkrat ponoviti.

\section{Majhni koraki, velike spremembe}

S poznavanjem razvojnih fazah mišljenja ter razumevanjem bolezni in bolečine dojenčkov, malčkov, otrok in mladostnikov lahko pomembno olajšamo stiske, ki spremljajo obisk nujne pomoči. S tem lahko olajšamo tudi svoje delo, saj spodbujamo sodelovanje, pozitiven odnos do osebja in zdravljenja ter s tem boljšo komunikacijo $s$ starši in nenazadnje bolj ugodne izide zdravljenja. Ne smemo pozabiti, da je lažje vzpostaviti pozitiven odnos z otrokom in starši kljub morebitnemu večjemu začetnemu vložku z naše strani, kot kasneje spreminjati negativnega.

\section{Literatura}

1. Bürger Lazar M, Sever M. Psihološki vidiki proceduralne bolečine pri otroku in uporaba kognitivno-vedenjskega pristopa. Psihološka obzorja 2020; 29: 42-51.

2. Myant KA, Williams JM. Children's concepts of health and illness: Understanding of contagious illnesses, non-contagious illnesses and injuries. J Health Psychol 2005; 10(6): 805-19.

3. Marjanovič Umek L, Zupančič M. 2009. Teorije psihičnega razvoja. In: Marjanovič Umek L, Zupančič M, eds. Razvojna psihologija. Ljubljana: Založba Rokus Klett 2009: 28-64.

4. Carson DK, Grayley JE, Council JR.1992. Children's prehospitalization conceptions of illness,

cognitive development, and personal adjustment. Child Health Care 1992; 21(2): 103-10.

5. Piko F, Back J. Children's perceptions of health and illness: Images and lay concepts in preado- lescence. Health Educ Res 2006; 21(5): 643-53.

6. Koopman HM, Barrs RM, Chaplin J, Zwinderman KH. 2005. Illness through the eyes of the child: The development of children's understanding of the causes of illness. Patient Educ Couns 2005; 55: 363-70.

Bürger Lazar M. Pomagati otroku zmanjšati strah in bolečino med zdravstvenim posegom. Ljubljana: Slovensko zdravniško društvo, Združenje za pediatrijo in Zbornica-Zveza, Sekcija medicinskih sester in zdravstvenih tehnikov v pediatriji; 2016.

8. Bibace R, Walsh ME. 1980. Development of children's concepts of illness. Pediatrics 1980; 66: 912-7.

9. Kovše M, Grosek Š. Otrokove razvojne značilnosti in odziv na stres. In: Grosek Š, eds. Kritično bolan in poškodovan otrok. Ljubljana: Univerzitetni klinični center, 2014: 149-53.

10. Anžič J, Bürger Lazar M, Jazbec J, Rožič M. Ko otrok zboli za rakom. Celje-Ljubljana: Ustanova za pomoč otroku z rakom in Celjska Mohorjeva družba; 2018.

11. Marin A. Concepts of ilness among children of different ethnicities, socioeconomic backgrounds, and genders (diplomsko delo). San Diego: San Diego State University; 2010.

12. Latour JM, Van Goudoever JB, Albres MJIJ, Van Dam NAM, Dullaart E, Van Herde M, Verlaat CWM, Van Vught EM, Hazelzet JA. A qualitative study exploring the experiences of parents of children admitted to seven Dutch pediatric intensive care units. Intensive Care Med 2011; 37: 319-25.

13. Mathew JE, Azariah J, George SE, Grewal SS. Do they hear what we speak? Assessing the effectiveness of communication to families of critically ill neurosurgical patients. J Anaesthesiol Clin Pharmacol 2015; 31(1): 49-53.

14. Piazza O, Cersosimo G. Communication as a basic skill in critical care. J Anaesthesiol Clin Pharmacol 2015; 31(3): 382-3.

15. Smith S, Hanson JL, Tewksbury LR, Christy C, Talib NJ, Harris MA. Teaching patient communication skills to medical students: A review of randomized controlled trials. Eval Health Prof 2007; 30: 3-21. 16. Street RL, Makoul NK, Arora RM, Epstein M. How does communication heal? Pathways linking clinician-patient communication to health outcomes. Patient Educ Couns 2009; 74: 295-301.

17. Taveria-Gomes I, Mota-Cardoso R, Figueiredo -Braga M. Communication skills in medical students - An exploratory study before and after clerkship. Porto Biomed J 2016; 1(5): 173-80.

Lara Šuštar Pennone, mag. psih. kontaktna oseba / contact person Razvojna ambulanta, Zdravstveni dom Ljubljana, Enota Bežigrad, PE Črnuče Primožičeva ulica 2, 1000 Ljubljana, Slovenija e-naslov: lara.pennone-sustar@zd-lj.si

prispelo/received: 6. 7. 2021 sprejeto/accepted: 19. 11. 2021

Šuštar Pennone L, Pomoč otroku v urgentni ambulanti. Slov Pediatr 2021; 28(4): 228-231. https://doi. org/10.38031/slovpediatr-2021-4-07. 